\title{
Lenalidomide induced good clinical response in a patient with multiple relapsed and refractory Hodgkin's lymphoma
}

\author{
Inga Mandac and Slobodanka Ostojic Kolonic*
}

\begin{abstract}
Background: A 24-year-old female patient was diagnosed with classic Hodgkin's lymphoma in clinical stage II, and combination chemotherapy followed by radiotherapy was initiated. During the following 5 years, the disease progressed despite several standard therapeutic approaches, including autologous and allogeneic stem cell transplantation.

Methods: Lenalidomide (25 mg daily) treatment was then initiated in a continuous dosing schedule. Positron emission tomography scans were performed before and during lenalidomide treatment. Hematologic and laboratory values, as well as physical condition were also assessed before and during lenalidomide treatment.

Results: Four months after continuous lenalidomide treatment, tumor load was significantly reduced, B symptoms had resolved, and the patient's physical condition had improved, allowing her to resume normal daily-living activities. Evaluations after 15 months of lenalidomide treatment indicated limited disease progression. Nevertheless, the patient was feeling well and maintaining a normal active life. Treatment was well tolerated, allowing the patient to remain on continuous dosing, which has now been maintained for 18 months.

Conclusion: Daily, long-term lenalidomide treatment provided clinical benefit and was well tolerated in a patient with relapsed, advanced classic Hodgkin's lymphoma.
\end{abstract}

\section{To the editor}

In February 2003, a 24-year-old female was diagnosed with classic Hodgkin's lymphoma in clinical stage II. Her initial treatment consisted of 6 cycles of ABVD followed by involved-field radiotherapy of the mediastinal mass, and resulted in complete remission until November 2004, when she suffered a relapse. After a peripheral blood stem cell harvest, she underwent high-dose BEAM chemotherapy and an autologous peripheral blood stem cell transplantation (SCT), which was completed in January 2005 and resulted in complete clinical remission. In October 2005 a second relapse occurred, characterized by infiltration of the malignancy into lymph nodes in the L1 region and pelvis. The patient was treated with radiotherapy to the pelvis and 3 cycles of standard dose BEACOPP resulting in partial remission lasting until

\footnotetext{
* Correspondence: ostojic@net.hr

1 Department of Internal Medicine, Merkur University Hospital, Zagreb, Croatia Full list of author information is available at the end of the article
}

September 2006. In October 2006 a donor was identified and an allogeneic SCT was performed resulting in a complete response until February 2008 when positron emission tomography (PET) and multislice spiral computed tomography scans identified relapse (Figure 1A). Chemotherapy with one cycle of LVPP did not produce a clinical response, so in April and May 2008 the patient underwent two cycles of gemcitabine: $1,000 \mathrm{mg} / \mathrm{m}^{2}$ on day 1 and day 8. A minor clinical response was observed but the patient's physical condition continued to worsen. Abdominal ultrasound revealed enlarged para-aortal, paracaval, mesenterial, and portal lymph nodes.

On June 25, 2008 treatment with continuous daily single-agent lenalidomide $(25 \mathrm{mg})$ was initiated, outside of a clinical trial setting and based on discussions at the 10th International Conference on Malignant Lymphoma, Lugano, Switzerland, 2008. Prior to treatment initiation, the patient's hematologic and laboratory values were within or close to the normal range (Table 1). By October 


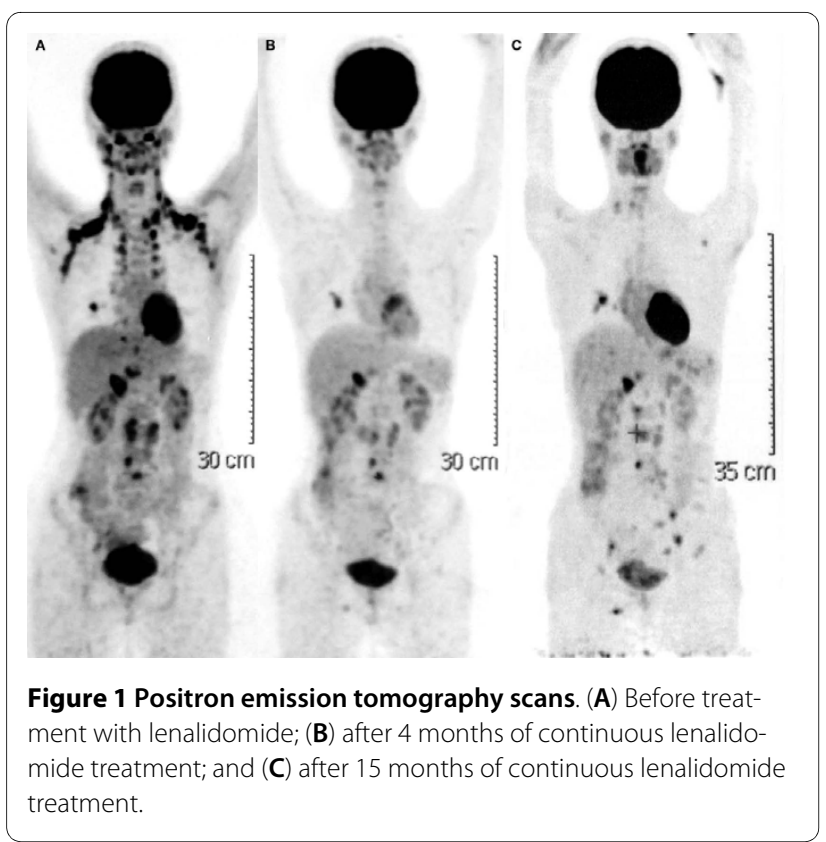

2008, after 4 months of continuous lenalidomide, B symptoms had resolved, and she was able to tolerate treatment with no evidence of either hematologic or nonhematologic toxicity. The patient's physical condition improved and she was able to resume normal daily activities, such as her university studies. A PET scan performed 4 months after continuous lenalidomide (Figure $1 B)$, revealed infiltrates in the middle lung lobe and in the right lobe, and the portal lymph node had shrunk. Metabolic activity was detected in the lungs and abdominal lymph nodes. The patient has remained on continuous lenalidomide since 2008. In a follow-up examination in August 2009 she was found to be in good physical condition and although her laboratory results showed mild leucopenia (World Health Organization hematologic toxicity scale grade 2), no dose reduction was required (Table 1). However, a third PET scan in September 2009 revealed new lesions in the lung, lymph nodes, and spleen, indicating disease progression (Figure 1C). Metabolic activity was detected in the lungs, left axillary lymph nodes, spleen, and vertebral column. Despite evidence of disease progression, the patient feels well, enjoys a good quality of life, is maintaining her university studies, and was able to go on vacation. She remains on continuous lenalidomide and her disease progression is expected to remain limited in the immediate future.

\section{Conclusions}

The lenalidomide dose selected for this patient was based on the standard dose used in multiple myeloma, nonHodgkin's lymphoma, and classic Hodgkin's lymphoma (25 mg daily for 21 days of every 28-day cycle) [1-4]. In this patient, no significant hematologic toxicity was detected with continuous lenalidomide, which has been ongoing for 18 months. The observed efficacy is consistent with data reported from two small studies [3,4]. Further clinical studies are needed to assess the clinical

Table 1: Results of laboratory tests before initiation of lenalidomide treatment and after 12 months of continuous treatment.

\begin{tabular}{|c|c|c|c|}
\hline Laboratory value & $\begin{array}{l}\text { Reference } \\
\text { range }\end{array}$ & $\begin{array}{c}\text { Values before } \\
\text { lenalidomide treatment }\end{array}$ & $\begin{array}{l}\text { Values after } 12 \text { months of } \\
\text { lenalidomide ( } 25 \mathrm{mg} / \text { day) treatment }\end{array}$ \\
\hline White cell count $\left(\times 10^{9} / \mathrm{L}\right)$ & 3.4-9.7 & 4.31 & 2.2 \\
\hline Red cell count $\left(\times 10^{12} / \mathrm{L}\right)$ & $3.86-5.08$ & 4.52 & 3.9 \\
\hline Hemoglobin $(\mathrm{g} / \mathrm{L})$ & 119-157 & 119 & 111 \\
\hline Hematocrit (L/L) & $0.356-0.470$ & 0.377 & 0.34 \\
\hline Platelet count $\left(\times 10^{9} / \mathrm{L}\right)$ & $158-424$ & 196 & 158 \\
\hline Mean corpuscular volume (fL) & $83.0-97.2$ & 83.4 & 83 \\
\hline Erythrocyte sedimentation rate (mm/3.6 ks) & $4-24$ & 26 & 26 \\
\hline Total protein $(\mathrm{g} / \mathrm{L})$ & $66-81$ & 70.5 & 67.2 \\
\hline C-reactive protein (mg/L) & $<5$ & 12.1 & Not done \\
\hline Lactate dehydrogenase $(\mathrm{U} / \mathrm{L})$ & $<241$ & 250 & 175 \\
\hline Aspartate aminotransferase $(\mathrm{U} / \mathrm{L})$ & $8-30$ & 20 & 16 \\
\hline Alanine aminotransferase $(\mathrm{U} / \mathrm{L})$ & $10-36$ & 6 & 16 \\
\hline Gamma-glutamyl transpeptidase (U/L) & $9-35$ & 15 & 10 \\
\hline Alkaline phosphatase (U/L) & $54-119$ & 147 & 124 \\
\hline Urea (mmol/L) & $2.8-8.3$ & 4.5 & 3.1 (blood urea) \\
\hline Creatinine (qmol/L) & 63-107 & 58 & 66 \\
\hline
\end{tabular}


utility of lenalidomide in this indication, and to inform prescribing decisions on the most appropriate dose regimen.

\section{Author Details}

Department of Internal Medicine, Merkur University Hospital, Zagreb, Croatia

Received: 29 April 2010 Accepted: 28 May 2010

Published: 28 May 2010

\section{References}

1. Wiernik PH, Lossos IS, Tuscano JM, Justice G, Vose JM, Cole CE, Lam W, McBride K, Wride K, Pietronigro D, Takeshita K, Ervin-Haynes A, Zeldis JB, Habermann TM: Lenalidomide monotherapy in relapsed or refractory aggressive non-Hodgkin's lymphoma. J Clin Oncol 2008, 26:4952-4957.

2. Witzig TE, Wiernik PH, Moore T, Reeder C, Cole C, Justice G, Kaplan H, Voralia M, Pietronigro D, Takeshita K, Ervin-Haynes A, Zeldis JB, Vose JM: Lenalidomide oral monotherapy produces durable responses in relapsed or refractory indolent non-Hodgkin's lymphoma. J Clin Oncol 2009, 27:5404-5409.

3. Fehniger TA, Larson S, Trinkhaus K, Siegel MJ, Cashen AF, Blum KA, Fenske TS, Hurd DD, Goy A, DiPersio JF, Bartlett NL: A phase II multicenter study of lenalidomide in relapsed or refractory classical Hodgkin lymphoma [abstract]. [http://ash.confex.com/ash/2009/webprogram/ Paper18377.html]

4. Böll B, Borchmann P, Topp MS, Hänel M, Reiners KS, Engert A, Naumann R: Lenalidomide in patients with refractory or multiple relapsed Hodgkin lymphoma. Br J Haematol 2010, 148:480-482.

doi: $10.1186 / 1756-8722-3-20$

Cite this article as: Mandac and Kolonic, Lenalidomide induced good clinical response in a patient with multiple relapsed and refractory Hodgkin's lymphoma Journal of Hematology \& Oncology 2010, 3:20

Submit your next manuscript to BioMed Central and take full advantage of:

- Convenient online submission

- Thorough peer review

- No space constraints or color figure charges

- Immediate publication on acceptance

- Inclusion in PubMed, CAS, Scopus and Google Scholar

- Research which is freely available for redistribution

Submit your manuscript at www.biomedcentral.com/submit 